\title{
Lixisenatide for Type 2 Diabetes Mellitus Patients Inadequately Controlled on Oral Antidiabetic Drugs: A Mixed-Treatment Comparison Meta-analysis and Cost-Utility Analysis
}

\author{
Peng Men (D) · Shuli Qu • Zhenqiang Song • Yanjun Liu • \\ Chaoyun Li $\cdot$ Suodi Zhai (D)
}

Received: May 9, 2020 / Published online: June 19, 2020

(c) The Author(s) 2020

\begin{abstract}
Introduction: The aim of this study was to compare the efficacy, safety and cost-utility (from the Chinese health insurance perspective) of lixisenatide and insulin regimens in patients with type 2 diabetes mellitus (T2DM) inadequately controlled on oral antidiabetic drugs (OADs).
\end{abstract}

Digital Features To view digital features for this article go to https://doi.org/10.6084/m9.figshare.12459482.

Electronic Supplementary Material The online version of this article (https://doi.org/10.1007/s13300020-00857-3) contains supplementary material, which is available to authorized users.

P. Men · S. Zhai $(\bowtie)$

Department of Pharmacy, Peking University Third Hospital, Beijing 100191, China

e-mail: zhaisuodi@163.com

\section{P. Men · S. Zhai}

Institute for Drug Evaluation, Peking University

Health Science Center, Beijing 100191, China

S. Qu · Y. Liu

Real-World Insights Division, IQVIA, Shanghai 200041, China

\section{Z. Song}

Tianjin Medical University Chu Hisen-I Memorial Hospital, Tianjin 300134, China

C. $\mathrm{Li}$

Health Economics and Outcome Research, Sanofi, Shanghai 200040, China
Methods: A comprehensive literature search of English (PubMed and Cochrane Library) and Chinese (CNKI and WanFang) language databases was performed, and head-to-head relevant randomized controlled trials (RCTs) were retrieved and analyzed by performing a mixedtreatment comparison (MTC) meta-analysis for efficacy and safety endpoints. A cost-utility analysis was then conducted using the IQVIA CORE Diabetes Model to compare the lifetime pharmacoeconomic profiles among the treatment groups.

Results: Eleven RCTs were included in this MTC meta-analysis. Regarding glycated hemoglobin targets, lixisenatide was similar to both basal insulin (mean difference [MD] 0.27\%; 95\% credible interval [CrI] $0.02 \%, 0.57 \%$ ) and premixed insulin (MD 0.32\%; 95\% CrI - 0.01\%, $0.66 \%)$, respectively. Statistically significant differences were found for changes in body weight in favor of lixisenatide compared with basal insulin (MD - 3.22 kg; 95\% CrI - $5.51 \mathrm{~kg}$, $-0.94 \mathrm{~kg})$ and premixed insulin $(\mathrm{MD}-2.68 \mathrm{~kg} ; 95 \% \mathrm{CrI}-5.16 \mathrm{~kg},-0.20 \mathrm{~kg})$. The relative risk (RR) of symptomatic hypoglycemia associated with lixisenatide was also significantly lower than that associated with basal insulin (RR 0.22; 95\% CrI 0.09, 0.52) and premixed insulin (RR 0.17; 95\% CrI 0.07, 0.41). The cost-utility analysis yielded results of $¥ 61,072$ (\$8565, vs. basal insulin) and $¥ 127,169$ $(\$ 17,836$, vs. premixed insulin) per quality-adjusted life year gained, with both values falling 
within the willingness-to-pay threshold in China.

Conclusions: For T2DM patients inadequately controlled on OADs, lixisenatide was shown to be comparable to basal insulin and premixed insulin in terms of HbA1c and better than both of the latter in terms of both body weight loss and hypoglycemia. Lixisenatide was also a costeffective treatment option from the perspective of Chinese health insurance.

Keywords: Chinese; Economics; GLP-1 analogue; Network meta-analysis; Type 2 diabetes

\section{Key Summary Points}

Why carry out this study?

The clinical effects and pharmacoeconomic profiles of lixisenatide versus both basal insulin and premixed insulin in type 2 diabetes mellitus (T2DM) patients inadequately controlled on oral antidiabetic drugs (OADs) have not yet been well reported.

The aim of the mixed-treatment comparison meta-analysis and cost-utility analysis reported here was to compare the efficacy, safety and cost-utility (from the Chinese health insurance perspective) of lixisenatide and insulin regimens in this population.

\section{What was learned from the study?}

The results showed that lixisenatide was comparable to basal insulin and premixed insulin in terms of HbA1c target and better than either of the latter medications in terms of both body weight loss and hypoglycemia in T2DM patients inadequately controlled on OADs.

Meanwhile, lixisenatide was shown to be a cost-effective treatment option from the perspective of Chinese health insurance in the above-mentioned patients.

\section{INTRODUCTION}

Diabetes is a global epidemic, with approximately 425 million adults aged 20-79 years (8.8\% of the world's population) worldwide estimated to have this disease in 2017 [1]. Among countries, China has the highest number of patients with diabetes, and the number are expected to rise substantially to 129.7 million in 2030 [2]. Type 2 diabetes mellitus (T2DM) accounts for 95\% of all diabetes cases.

T2DM is generally initially treated with one or two oral antidiabetic drugs (OADs), with most treatment regimens including metformin. However, the prevalence of uncontrolled blood sugar in persons with T2DM treated with OADs rises with increasing duration of diabetes, increasing from $23.7 \%$ in patients with a disease duration of $<5$ years to $39.3,57.1$ and $75.9 \%$ among those with a disease duration of 5-9.9, $10-19.9$ and $\geq 20$ years, respectively [3]. Following the failure of treatments with OADs, other medications are recommended, with insulin therapies regarded as the mainstay of treatment for T2DM [4].

The emergence of glucagon-like peptide- 1 receptor agonists (GLP-1 RAs) has provided a new treatment option. GLP-1 RAs are able to lower blood glucose levels by stimulating the incretin system, enhancing the secretion of insulin from pancreatic $\beta$-cells in response to ingested glucose, slowing gastric emptying, and augmenting satiety [5]. Lixisenatide, a oncedaily GLP-1 RA, is effective in reducing the glycated hemoglobin (HbAc1) level in patients with T2DM by lowering both the fasting and the postprandial blood glucose levels [6].

To date, only one head-to-head randomized controlled trial (RCT) has been conducted on the efficacy and safety of lixisenatide versus basal insulin in T2DM patients inadequately controlled on OADs [2], and as yet there has been no direct comparison in RCTs of lixisenatide and premixed insulin in terms of efficacy and safety. Given this lack of data from RCTs, a mixed-treatment comparison (MTC) may provide useful insights to support clinical and policy decision-making. The aim of this study was to compare the efficacy, safety and 
cost-utility of lixisenatide, basal insulin and premixed insulin in patients with T2DM inadequately controlled on one to two OADs from the Chinese health insurance perspective.

\section{METHODS}

\section{Systematic Review and MTC}

\section{Identification of Eligible Trials and Data Extraction}

A comprehensive literature search of head-tohead clinical RCTs involving T2DM patients inadequately controlled on one to two OADs was performed. Interventions were lixisenatide, basal insulin, premixed insulin and placebo. PubMed and Cochrane Library databases were searched for trials published in English, and the CNKI and WanFang databases were searched for studies published in Chinese, all up to July 2018. The inclusion criteria and full search strategies are presented in Electronic Supplementary Material (ESM) Appendices S1 and S2.

Identification of the trials to be included in the MTC and the extraction of data were performed independently by two authors. Any discrepancies were reconciled by a third author. The risk of bias for each RCT included in the study was assessed using the Cochrane Collaboration's Risk of Bias tool (ESM Appendices S1, S2) [7].

This article is based on previously conducted studies and does not contain any studies with human participants or animals performed by any of the authors.

\section{Analysis Methods}

To conduct the MTC, we used the Bayesian framework with random-effects hierarchical models to perform network meta-analysis (NMA) according to the guidance from the UK National Institute for Health and Care Excellence (NICE) [8], using STATA ${ }^{\circledR}$ software (ver. 13.0; StataCorp, College Station, TX, USA). The relative effect sizes were estimated as mean differences (MDs) for continuous outcomes and relative risks (RRs) for dichotomous outcomes. Both types of effect sizes were reported with their 95\% credible intervals (CrIs). A non- informative prior was chosen as prior distribution as there was a large difference in the outcome scale of the analysis. The posterior distribution was estimated using the Markov Chain Monte Carlo method. The loop-specific approach was used to evaluate the presence of inconsistency in each closed loop. The nodesplitting method was used to assess the inconsistency of the model. The $Z$ score and their associated $p$ values for every closed-loop identified in the network were calculated under the assumption of the absence of inconsistency. The goodness of model fit was evaluated by comparing the deviance information criterion between the random-effect and fixed-effect model. The Grading of Recommendations and Assessment, Development, and Evaluation (GRADE) approach was applied to appraise the evidence of the results.

\section{Cost-Utility Analysis}

\section{Model Overview}

The cost-utility analysis (CUA) was conducted using the IQVIA CORE Diabetes Model (CORE model) to compare the lifetime pharmacoeconomic profiles among the lixisenatide, basal insulin, and premixed insulin treatment groups. The CORE model is a widely-used, web-based commercial health economic model that has been previously validated against 66 published studies, including second- (internal) and third(external) order validation of simulations of T2DM [9]. The CORE model captures the longterm and progressive nature of diabetes and the interactivity of its complications through its combination of Monte Carlo simulation and Markov modeling. The simulations were performed over a lifetime horizon in order to fully capture the mortality rates and long-term complications of T2DM and associated medical costs.

\section{Model Inputs}

Baseline Cohort Characteristics The baseline demographics and biochemical parameters of the modeled cohort were derived from the GetGoal-M-Asia trial [2], which included only Asian patients (Chinese patients $>90 \%$ ) with 
T2DM inadequately controlled on one to two OADs, and supplemented with data from the literature where necessary [10-13]. Detailed baseline cohort characteristics are listed in ESM Appendix S3.

Treatment Effects According to the setting of the CORE model, treatment effects incorporated in our analysis included the changes from baseline in HbA1c and body weight (body mass index [BMI]), as well as rates of hypoglycemia events. Since body weight change itself cannot be imputed in the CORE model directly, the BMI was applied instead. The treatment effects in the basal insulin and premixed insulin groups were calculated based on comparisons with the data in the lixisenatide group and the relative treatment effects from the results of the MTC. The treatment effects in the lixisenatide group were derived from the GetGoal-M-Asia clinical trial. The clinical input parameters of each treatment arm are listed in Table 1 . The treatment effects applied in the first year of the analysis were based on the NMA using trial data over a period of 24-30 weeks. Patients were assumed to receive the intervention or comparator treatment before therapy was intensified. After intensification, HbA1c, BMI, hypoglycemic event rates, and annual costs of T2DM interventions were the same in all treatment arms, with immediate abolition of relative treatment effects representing a conservative modeling approach.
Utilities The utility and disutility values of various T2DM states and complications were derived from published studies [14-20]. Regarding the influence of excess BMI on the quality of life, we applied a disutility of 0.0061 for each unit of BMI over $25 \mathrm{~kg} / \mathrm{m}^{2}$, which is in line with the published time trade-off analysis from the CODE-2 study [21].

Costs This CUA was performed from the Chinese health insurance perspective; consequently, only direct medical costs were included in the analysis, including medication acquisition costs, management costs for diabetes-related complications and routine patient management costs. All cost data are reported in the 2017 Chinese yuan (¥). Costs were also converted into US dollars (\$) for improving the international compatibility of the results ( $\$ 1=¥ 7.13)$. The medication acquisition costs were obtained from the China Hospital Pharmaceutical Audit (CHPA) database. The daily costs of lixisenatide, premixed insulin and basal insulin were $¥ 30$, $¥ 4$, and $¥ 11(\$ 4, \$ 1$, and $\$ 2$ ), respectively. Costs for the management of diabetes-related complications in the year of the event and the respective annual follow-up costs (each year of the simulation subsequent to the event) are listed in ESM Appendices S4-S6; these were mainly calculated from a study estimating the direct medical costs of diabetes-related complications using the sampling claims data collected by the China Health Insurance Research Association (CHIRA) [22].

Table 1 Treatment effects applied in the cost-utility analysis

\begin{tabular}{llllc}
\hline Terms & $\begin{array}{l}\text { HbA1c change from } \\
\text { baseline (\%) }\end{array}$ & $\begin{array}{l}\text { BMI change from } \\
\text { baseline }(\mathbf{k g})\end{array}$ & $\begin{array}{l}\text { Symptomatic hypoglycemia (events per } \\
\mathbf{1 0 0} \text { patient-year) }\end{array}$ & Source \\
\hline Lixisenatide & -0.83 & -0.56 & 20.00 & $\begin{array}{c}\text { Pan et al. } \\
{[2]}\end{array}$ \\
$\begin{array}{c}\text { Premixed } \\
\text { insulin }\end{array}$ & -1.15 & 0.44 & 119.20 & This \\
$\begin{array}{c}\text { Basal } \\
\text { insulin }\end{array}$ & -1.10 & 0.64 & 90.91 & MTC \\
$\begin{array}{l}\text { Placebo } \\
\text { - }\end{array}$ & & & This \\
& & -0.063 & 13.00 & MTC \\
\hline
\end{tabular}

$B M I$ Body mass index, $H b A l c$ hemoglobin Alc (glycated hemoglobin), $M T C$ mixed-treatment comparison 


\section{Base-Case analysis}

Direct medical costs, life-years and quality-adjusted life-years (QALYs) gained in the three different treatment groups were calculated. The results of the CUA were evaluated by calculating the incremental cost per QALY gained, i.e. the incremental cost-utility ratio (ICUR). Both costs and clinical outcomes were discounted at an annual rate of $3 \%$ per year [23]. A value of threefold the 2018 annual gross domestic product (GDP) per capita, as recommended by the Commission on Macroeconomics and Health of the World Health Organization [24], was regarded as the willingness-to-pay threshold (WTP; $¥ 193,562 / \$ 27,148$ per QALY) [25] of the base-case analysis according to the local pharmacoeconomic guidelines [23].

\section{Sensitivity Analysis}

In order to assess the impact of variations in the key parameters on cost-utility results, we performed a series of one-way and probabilistic sensitivity analyses.

One-Way Sensitivity Analysis The one-way sensitivity analysis (OWSA) involved the discounting rate of costs and clinical outcomes $(0$ or $5 \%)$, costs of all diabetes complications $( \pm 25 \%)$, health state utility and event disutility values $( \pm 25 \%)$, changes in HbA1c from baseline (the upper limit and lower limit of the 95\% credible interval), changes in BMI from baseline $( \pm 25 \%)$ and time horizon (20 years).

Probabilistic Sensitivity Analysis A Monte Carlo simulation with 1000 iterations was used to perform the probabilistic sensitivity analysis (PSA) with parameter inputs (utilities, complication costs, treatment effects, cohort characteristics, and clinical events) sampled from fixed distributions with the mean and standard deviation values. The results were then used to calculate the mean and 95\% confidence intervals of QALYs, costs, and ICURs. Scatterplots and cost-utility acceptability curves were drawn to further illustrate the results.

\section{RESULTS}

\section{Literature Review Results}

The titles and abstracts of 2035 potentially eligible studies for inclusion in the MTC metaanalysis were screened. After removal of all duplicated studies and screebubg if abstracts, 283 potentially relevant citations were identified for full-text screening. Ultimately, 11 trials with 4511 patients were included (ESM Appendix S7) [2, 26-35].

The baseline characteristics of the included studies are given in ESM Appendix S8. The mean age, gender, BMI, HbA1c, fasting plasma glucose (FPG) and diabetes duration were similar across all studies. At baseline, patients in the included trials had a mean age of 55.9 years, mean BMI of $29.1 \mathrm{~kg} / \mathrm{m}^{2}$, mean HbA1c of $8.3 \%$, mean FPG of $9.4 \mathrm{mmol} / \mathrm{L}$ and mean diabetes duration of 7.7 years. The trials were considered to have low/moderate-risk of bias based on assessment using the Cochrane Risk of Bias Assessment tool [7]. There was no study reporting items that were assessed to have a high risk of bias (ESM Appendix S9).

\section{MTC Results}

The network relationships of evidence included in the MTC are shown in Fig. 1. Results for pairwise comparisons are shown in ESM Appendix S10.

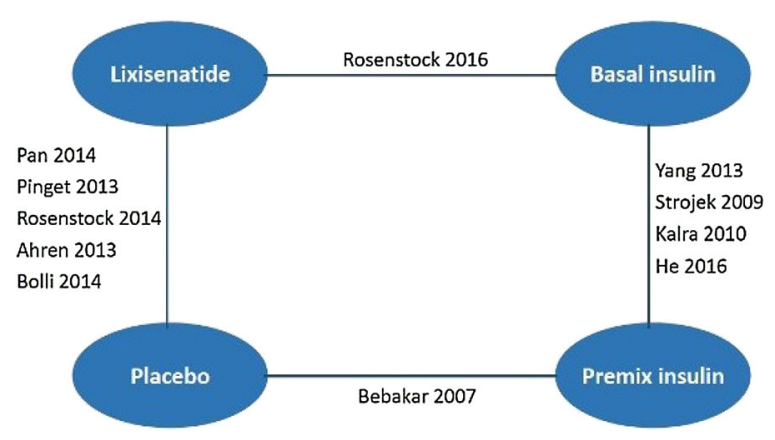

Fig. 1 Evidence network of the mixed-treatment comparison. First author and year of publication are shown 


\section{Mean Changes in the HbA1c and FPG Levels from Baseline}

There was no statistically significant difference in $\mathrm{HbA1c}$ reduction from baseline between lixisenatide and basal insulin (MD 0.27\%; 95\% CrI $-0.02 \%, 0.57 \%$ ) and lixisenatide and premixed insulin (MD 0.32\%; 95\% CrI - 0.01\%, $0.66 \%$ ). Basal insulin was associated with a statistically significant greater reduction in FPG from baseline compared with lixisenatide (MD
$1.78 \mathrm{mmol} / \mathrm{L} ; 95 \%$ CrI $1.51 \mathrm{mmol} / \mathrm{L}, 2.06$ $\mathrm{mmol} / \mathrm{L})$. The difference in FPG reduction between lixisenatide and premixed insulin was not significant (MD $-0.03 \mathrm{mmol} / \mathrm{L} ; 95 \% \mathrm{CrI}$ - $0.71 \mathrm{mmol} / \mathrm{L}, 0.65 \mathrm{mmol} / \mathrm{L}$ ) (Fig. 2).

\section{Mean Change in Body Weight from Baseline}

The change in body weight from baseline was significantly greater in patients receiving lixisenatide than in those on basal insulin (MD

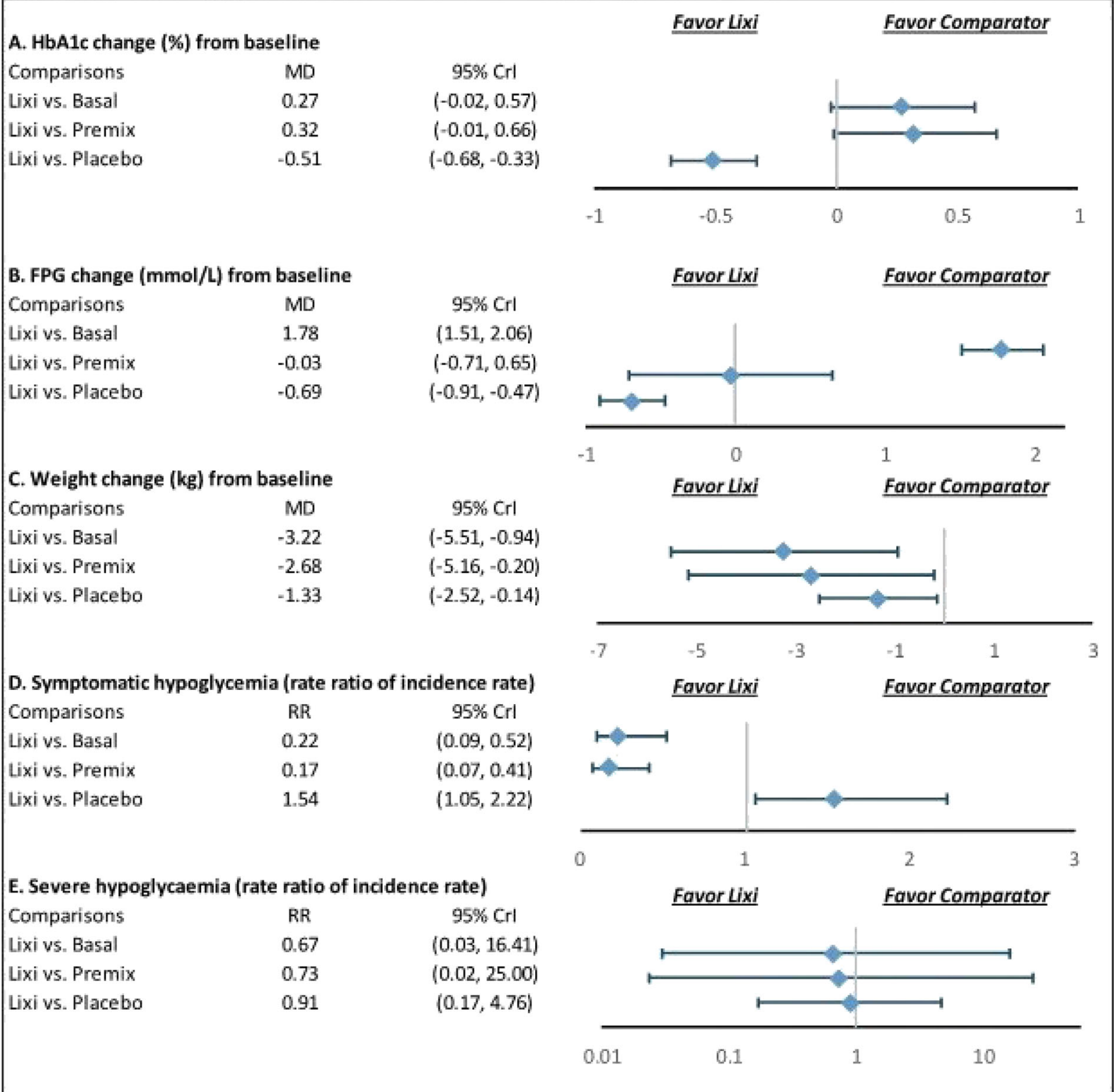

Fig. 2 Summary plots of the mixed-treatment comparison results. $C r I$ Credible interval, $F P G$ Fasting plasma glucose, $H b A 1 c$ hemoglobin Alc (glycated hemoglobin), Lixi lixisenatide, $M D$ mean difference, $R R$ risk ratio 
Table 2 Summary of the base-case analysis results of the cost-utility analysis

\begin{tabular}{lccccccc}
\hline $\begin{array}{l}\text { Items targeted } \\
\text { in base-case } \\
\text { analysis }\end{array}$ & Lixisenatide & \multicolumn{2}{l}{ vs. Comparators } & & & \\
\cline { 3 - 7 } & & Basal insulin & $\begin{array}{l}\Delta \\
\text { Mean }\end{array}$ & $\begin{array}{l}\text { Premixed } \\
\text { insulin }\end{array}$ & $\Delta$ Mean & Placebo & $\begin{array}{l}\Delta \\
\text { Mean }\end{array}$ \\
\hline $\begin{array}{l}\text { Life expectancy } \\
\quad \text { years) }\end{array}$ & $16.84(0.21)$ & $16.88(0.20)$ & -0.04 & $16.88(0.21)$ & -0.037 & $16.75(0.2)$ & 0.084 \\
QALY & & & & & & & \\
Direct costs (¥) & $391,685(10,217)$ & $386,090(9916)$ & 5594 & $382,414(10,529)$ & 9271 & $387,941(11,333)$ & 3744 \\
$\begin{array}{l}\text { ICUR (QALY, } \\
\quad)\end{array}$ & & & 61,072 & & 1127,169 & & 27,978 \\
\hline
\end{tabular}

Values in table are presented as the mean, with the standard deviation given in parenthesis as appropriate $B I$ Basal insulin, $¥$ Chinese Yuan, ICUR incremental cost-utility ratio, $Q A L Y$ quality-adjusted life-year

- $3.22 \mathrm{~kg} ; 95 \% \mathrm{CrI}-5.51 \mathrm{~kg},-0.94 \mathrm{~kg})$ and premixed insulin (MD $-2.68 \mathrm{~kg} ; 95 \% \mathrm{CrI}$ $-5.16 \mathrm{~kg},-0.20 \mathrm{~kg}$ ) (Fig. 2).

\section{Incidence Rate of Symptomatic and Severe Hypoglycemia}

Symptomatic hypoglycemia and severe hypoglycemia refer to clinical symptoms when the plasma glucose level is $<3.1$ and $2.0 \mathrm{mmol} / \mathrm{L}$, respectively, with prompt recovery after oral carbohydrate administration. In this MTC, the incidence of symptomatic hypoglycemia was significantly lower in patients on lixisenatide than in those on basal insulin (RR 0.22; 95\% CrI $0.09,0.52$ ) and premixed insulin (MD 0.17; 95\% CrI $0.07,0.41)$, respectively. The difference in the incidence of severe hypoglycemia was not significant between the lixisenatide and basal insulin treatment arms (RR 0.67; 95\% CrI 0.03, 16.41) and between the lixisenatide and premixed insulin treatment arms (RR 0.73; 95\% CrI 0.02, 25.00) (Fig. 2).

\section{Inconsistency, Model Fitness, Heterogeneity, and Evidence Appraisal}

We did not note significant inconsistencies between evidence derived from direct and indirect comparisons in any analyses, irrespective of the method of inconsistency assessment (ESM Appendix S11). A small $I^{2}$ statistic indicated a low heterogeneity (ESM Appendix S12). The results of the GRADE appraisal were shown in ESM Appendix S13.

\section{CUA Results}

\section{Base-Case Analysis}

Lixisenatide was associated with an incremental benefit of 0.073 QALYs and an increased cost of $¥ 9271$ (\$1300) compared with the premixed insulin. According to the WTP threshold, lixisenatide was a cost-effective option, with an ICUR of $¥ 127,169(\$ 17,836)$ per QALY gained. Lixisenatide was also cost-effective compared with basal insulin (ICUR $¥ 61,072 / \$ 8,565$ per QALY gained). The detailed results of this analysis are shown in Table 2 .

\section{Sensitivity Analyses}

The OWSA showed that the results were robust to parameter changes. Lixisenatide remained cost-effective compared with the other three interventions in the majority of scenarios investigated (Table 3).

The PSA showed that the likelihoods of lixisenatide being considered cost-effective at a WTP threshold of $¥ 193,562(\$ 27,148)$ per QALY gained were $63.2 \%$ and $54.7 \%$ for basal insulin and premixed insulin as comparators, respectively (ESM Appendices S14, S15).

\section{DISCUSSION}

To our knowledge, this is the first study to evaluate the comparative efficacy, safety and long-term cost-utility of lixisenatide versus 
Table 3 One-way sensitivity analysis of the cost-utility analysis

\begin{tabular}{|c|c|c|c|}
\hline Sensitivity analysis & $\begin{array}{l}\text { vs. Basal } \\
\text { insulin } \\
\text { (ICUR) }\end{array}$ & $\begin{array}{l}\text { vs. } \\
\text { Premixed } \\
\text { insulin } \\
\text { (ICUR) }\end{array}$ & $\begin{array}{l}\text { vs. } \\
\text { Placebo } \\
\text { (ICUR) }\end{array}$ \\
\hline Base case & 61,072 & 127,169 & 27,978 \\
\hline $\begin{array}{l}0 \% \text { discount rates for } \\
\text { costs and clinical } \\
\text { outcomes }\end{array}$ & 33,441 & 90,470 & 5985 \\
\hline $\begin{array}{l}5 \% \text { discount rates for } \\
\text { costs and clinical } \\
\text { outcomes }\end{array}$ & 76,175 & 146,776 & 48,867 \\
\hline $\begin{array}{l}\text { Complication costs } \\
\text { increased by } 25 \%\end{array}$ & 60,685 & 131,393 & 15,540 \\
\hline $\begin{array}{l}\text { Complication costs } \\
\text { decreased by } 25 \%\end{array}$ & 61,147 & 122,567 & 40,673 \\
\hline $\begin{array}{l}\text { Utility increased by } \\
25 \%\end{array}$ & 68,389 & 146,919 & 24,120 \\
\hline $\begin{array}{l}\text { Utility decreased by } \\
25 \%\end{array}$ & 55,170 & 112,099 & 33,276 \\
\hline $\begin{array}{l}\text { Upper limit of } 95 \% \\
\text { CrI for the change } \\
\text { in HbAlc from } \\
\text { baseline }\end{array}$ & 63,988 & 93,968 & 42,733 \\
\hline $\begin{array}{l}\text { Lower limit of } 95 \% \\
\text { CrI for the change } \\
\text { in HbAlc from } \\
\text { baseline }\end{array}$ & 61,428 & 167,236 & 33,329 \\
\hline $\begin{array}{l}\text { BMI change from } \\
\text { baseline increased } \\
\text { by } 25 \%\end{array}$ & 70,664 & 132,661 & 33,047 \\
\hline $\begin{array}{l}\text { BMI change from } \\
\text { baseline decreased } \\
\text { by } 25 \%\end{array}$ & 70,072 & 111,543 & 26,787 \\
\hline 20-year time horizon & 80,420 & 145,848 & 63,511 \\
\hline
\end{tabular}

CrlI Credible interval

basal insulin and premixed insulin, respectively, for patients with T2DM inadequately controlled on one to two OADs.
The risk of diabetes-related complications in T2DM patients is reported to be dependent on blood glucose levels and, consequently, glycemic control is fundamental to the management of diabetes. The results of our MTC, based on 11 studies involving 4511 adult T2DM patients inadequately controlled on OADs, suggest that the ability of lixisenatide to control glycemic level is similar to that of basal insulin and premixed insulin. In addition to the efficacy of the medication, adverse effects commonly associated with insulin therapies, such as weight gain and hypoglycemia events, also have a significant impact on the patient's (quality of) life and pose a substantial cost burden through increased treatment costs and reduced productivity. GLP-1 RAs, such as lixisenatide, can promote satiety and suppress energy intake and thus have a significant beneficial value in terms of weight control compared with insulins [36]. In addition, lixisenatide was associated with a significantly lower hypoglycemia risk in our NMA, indicating that it should be a more tolerable treatment option. It should be noted that although there were no statistical differences between the lixisenatide treatment arm and basal/premixed insulin treatment arms in terms of HbA1c level, the reduction in HbA1c was numerically greater in the basal or premixed insulin arms than in the lixisenatide arm.

Given the limited healthcare resources in China, the pharmacoeconomic profiles of therapies are regarded as important reference factors affecting healthcare decision-making. In our study, after extrapolating the short-term treatment effects to predict the long-term effects and corresponding costs, we found that lixisenatide, in comparison with basal insulin and premixed insulin, achieved a higher gain in QALYs and was associated with higher direct medical costs over a lifetime horizon. Assuming the WTP threshold was set at three times the GDP per capita in China, lixisenatide is a cost-effective option compared with premixed insulin and basal insulin. A series of one-way and probabilistic sensitivity analyses confirmed the robustness of our outcomes. Moreover, recent analyses have focused on the cost-effectiveness of combination therapy with lixisenatide + basal insulin versus other insulin regimens in 
T2DM patients inadequately controlled on basal insulin alone, with the results showing that combination therapy with lixisenatide + basal insulin is a cost-effective option in China [37] and the Republic of Korea [38].

There are a number of limitations to our study. First, although the population criterion was T2DM patients whose blood sugar level was inadequately controlled on one to two OADs, some trials included patients previously treated with one OAD (metformin) while others included patients treated with two OADs (metformin plus another drug, mostly a sulphonylurea). This variability may have affected the homogeneity of the population. However, the pooling of such populations was required to ensure network connectivity. Secondly, no RCT included in this MTC had a duration of $>30$ weeks. Thus, more data are needed to clarify the longterm sustained efficacy and ability to differentiate lixisenatide from basal/premixed insulin. Thirdly, there was a lack of direct comparisons between lixisenatide and premixed insulin, which may have resulted in a greater emphasis on the consistency between direct and indirect evidence. However, in the analysis there was no hint of any evidence of inconsistency. Also, only one study that directly compared lixisenatide to basal insulin was found and included in the MTC. Finally, the transition probabilities and disease progressions used in the CORE Model are based on the UK Prospective Diabetes Study (UKPDS) survey rather than on the Chinese population. Since there are as yet no longterm follow-up data available on Chinese diabetes patients, studies on Western populations are the best source of relevant data. The CUA was based on the assumption that the reduction of symptomatic hypoglycemia and prevention of weight gain that was demonstrated in the MTC can be extrapolated to the lifetime case, which may increase the uncertainty. Caution should be taken in interpreting and utilizing these results.

\section{CONCLUSION}

In summary, lixisenatide showed a similar capacity to basal insulin and premixed insulin to reduce $\mathrm{HbA1c}$, but showed a significantly lower risk of hypoglycemia and a greater body weight loss. Based on this MTC, lixisenatide is a cost-effective treatment alternative for patients with T2DM inadequately controlled on OADs in China, compared with basal insulin and premixed insulin.

\section{ACKNOWLEDGEMENTS}

Funding. This study and the Rapid Service Fee were funded by Sanofi China.

Authorship. All named authors meet the International Committee of Medical Journal Editors (ICMJE) criteria for authorship for this article, take responsibility for the integrity of the work as a whole, and have given their approval for this version to be published.

Prior Presentation. Part of this study was presented at the annual conference of International Society for Pharmacoeconomics and Outcomes Research Sessions, New Orleans, LA, USA, 18-22 May 2019.

Disclosures. Shuli Qu and Yanjun Liu have received research fees in related to the study. Chaoyun $\mathrm{Li}$ is an employee of Sanofi China. Peng Men, Zhenqiang Song, and Suodi Zhai have nothing to disclose.

Compliance with Ethics Guidelines. This article is based on previously conducted studies and does not contain any studies with human participants or animals performed by any of the authors.

Data Availability. The datasets generated during and/or analyzed during the current study are available from the corresponding author on reasonable request.

Open Access. This article is licensed under a Creative Commons Attribution-NonCommercial 4.0 International License, which permits any non-commercial use, sharing, adaptation, distribution and reproduction in any medium 
or format, as long as you give appropriate credit to the original author(s) and the source, provide a link to the Creative Commons licence, and indicate if changes were made. The images or other third party material in this article are included in the article's Creative Commons licence, unless indicated otherwise in a credit line to the material. If material is not included in the article's Creative Commons licence and your intended use is not permitted by statutory regulation or exceeds the permitted use, you will need to obtain permission directly from the copyright holder. To view a copy of this licence, visit http://creativecommons.org/licenses/by$\mathrm{nc} / 4.0 /$.

\section{REFERENCES}

1. International Diabetes Federation. IDF diabetes atlas. 8th ed. Brussels: International Diabetes Federation; 2017.

2. Pan CY, Han P, Liu X, et al. Lixisenatide treatment improves glycaemic control in Asian patients with type 2 diabetes mellitus inadequately controlled on metformin with or without sulfonylurea: a randomized, double-blind, placebo-controlled, 24-week trial (GetGoal-M-Asia). Diabetes Metab Res Rev. 2014;30(8):726-35.

3. Tong PC, Ko GT, So W-Y, et al. Use of anti-diabetic drugs and glycaemic control in type 2 diabetes-the Hong Kong Diabetes Registry. Diabetes Res Clin Pract. 2008;82(3):346-52.

4. Diabetes Society of Chinese Medical Association. Guidelines for the prevention and treatment of type 2 diabetes in China (2017 edition). Chin J Diabetes. 2018;10(1):4-67.

5. Nauck MA, Meier JJ. The incretin effect in healthy individuals and those with type 2 diabetes: physiology, pathophysiology, and response to therapeutic interventions. Lancet Diabetes Endocrinol. 2016;4(6):525-36.

6. Pfeffer MA, Claggett B, Diaz R, et al. Lixisenatide in patients with type 2 diabetes and acute coronary syndrome. N Engl J Med. 2015;373(23):2247-57.

7. Higgins JP, Altman DG, Gøtzsche PC, et al. The Cochrane Collaboration's tool for assessing risk of bias in randomised trials. BMJ. 2011;343:d5928.
8. Dias S, Welton NJ, Sutton AJ, Ades A. NICE DSU technical support document 2: a generalised linear modelling framework for pairwise and network meta-analysis of randomised controlled trials. (Technical support document in evidence synthesis; no. TSD2). 2011. http://www.nicedsu.org.uk.

9. Palmera AJ, Rozea S, Valentinea WJ, et al. Validation of the CORE diabetes model against epidemiological and clinical studies. Curr Med Res Opin. 2004;20(Supp1):S27-S40.

10. Ji L, Lu J, Guo X, et al. Glycemic control among patients in China with type 2 diabetes mellitus receiving oral drugs or injectables. BMC Public Health. 2013;13(1):602.

11. Nan Y, Xi Z, Yang Y, et al. The 2015 China Adult Tobacco Survey: exposure to second-hand smoke among adults aged 15 and above and their support to policy on banning smoking in public places. Zhonghua Liu Xing Bing Xue Za Zhi. 2016;37(6): 810-5.

12. World Health Organization. Global status report on alcohol and health, 2014. Geneva: World Health Organization; 2014.

13. Wang L, Gao P, Zhang $\mathrm{M}$, et al. Prevalence and ethnic pattern of diabetes and prediabetes in China in 2013. JAMA. 2017;317(24):2515-23.

14. Adler AI, Stratton IM, Neil HAW, et al. Association of systolic blood pressure with macrovascular and microvascular complications of type 2 diabetes (UKPDS 36): prospective observational study. BMJ. 2000;321(7258):412-9.

15. Clarke P, Gray A, Briggs A, et al. A model to estimate the lifetime health outcomes of patients with type 2 diabetes: the United Kingdom Prospective Diabetes Study (UKPDS) Outcomes Model (UKPDS no. 68). Diabetologia. 2004;47(10):1747-59.

16. UK Prospective Diabetes Study Group. Intensive blood-glucose control with sulphonylureas or insulin compared with conventional treatment and risk of complications in patients with type 2 diabetes (UKPDS 33). Lancet. 1998;352(9131):837-53.

17. UK Prospective Diabetes Study Group. Effect of intensive blood-glucose control with metformin on complications in overweight patients with type 2 diabetes (UKPDS 34). Lancet. 1998;352(9131): 854-65

18. Kothari V, Stevens RJ, Adler AI, et al. UKPDS 60: risk of stroke in type 2 diabetes estimated by the UK prospective diabetes study risk engine. Stroke. 2002;33(7):1776-811. 
19. Matza LS, Boye KS, Yurgin N, et al. Utilities and disutilities for type 2 diabetes treatment-related attributes. Qual Life Res. 2007;16(7):1251-65.

20. Turner RC, Cull CA, Frighi V, Holman RR, Group UPDS. Glycemic control with diet, sulfonylurea, metformin, or insulin in patients with type 2 diabetes mellitus: progressive requirement for multiple therapies (UKPDS 49). JAMA. 1999;281(21): 2005-122.

21. Bagust A, Beale S. Modelling EuroQol health-related utility values for diabetic complications from CODE-2 data. Health Econ. 2005;14(3):217-30.

22. Duan X, Li Y, Liu Q, Liu L, Li C. Epidemiological characteristics, medical costs and healthcare resource utilization of diabetes-related complications among Chinese patients with type 2 diabetes mellitus. Expert Rev Pharmacoecon Outcomes Res. 2019;1-9. https://doi.org/10.1080/14737167.2019. 1661777.

23. Liu G, Hu S, Wu J, Dong Z, Li H. China guidelines for pharmacoeconomic evaluations. Beijing: Science Press; 2019.

24. Marseille E, Larson B, Kazi DS, Kahn JG, Rosen S. Thresholds for the cost-effectiveness of interventions: alternative approaches. Bull World Health Organ. 2014;93:118-24.

25. National Bureau of Statistics of China. National data. 2020. https://data.stats.gov.cn/. Accessed 4 Sep 2020.

26. Ahrén B, Dimas AL, Miossec P, Saubadu S, Aronson R. Efficacy and safety of lixisenatide once-daily morning or evening injections in type 2 diabetes inadequately controlled on metformin (GetGoalM). Diabetes Care. 2013;36(9):2543-50.

27. Bebakar W, Chow C, Kadir K, et al. Adding biphasic insulin aspart 30 once or twice daily is more efficacious than optimizing oral antidiabetic treatment in patients with type 2 diabetes. Diabetes Obes Metab. 2007;9(5):724-32.

28. Bolli G, Munteanu M, Dotsenko S, et al. Efficacy and safety of lixisenatide once daily vs. placebo in people with Type 2 diabetes insufficiently controlled on metformin (GetGoal-F1). Diabetic Med. 2014;31(2):176-84.

29. He X, Li H, Luo Y. Clinical effects of insulin analogue once daily in blood sugar control substandard patients with tylpe 2 diabetes. Chongqing Med. 2016;45(34):4811-3.
30. Kalra S, Plata-Que T, Kumar D, et al. Initiation with once-daily BIAsp 30 results in superior outcome compared to insulin glargine in Asians with type 2 diabetes inadequately controlled by oral anti-diabetic drugs. Diabetes Res Clin Pract. 2010;88(3): 282-8.

31. Pinget M, Goldenberg R, Niemoeller E, et al. Efficacy and safety of lixisenatide once daily versus placebo in type 2 diabetes insufficiently controlled on pioglitazone (GetGoal-P). Diabetes Obes Metab. 2013;15(11):1000-7.

32. Rosenstock J, Aronson R, Grunberger G, et al. Benefits of LixiLan, a titratable fixed-ratio combination of insulin glargine plus lixisenatide, versus insulin glargine and lixisenatide monocomponents in type 2 diabetes inadequately controlled with oral agents: the LixiLan-O randomized trial. Diabetes Care. 2016;39(11):2026-35.

33. Rosenstock J, Hanefeld M, Shamanna P, et al. Beneficial effects of once-daily lixisenatide on overall and postprandial glycemic levels without significant excess of hypoglycemia in type 2 diabetes inadequately controlled on a sulfonylurea with or without metformin (GetGoal-S). J Diabetes Complications. 2014;28(3):386-92.

34. Strojek K, Bebakar WM, Khutsoane DT, et al. Oncedaily initiation with biphasic insulin aspart 30 versus insulin glargine in patients with type 2 diabetes inadequately controlled with oral drugs: an open-label, multinational RCT. Cur Med Res Opin. 2009;25(12):2887-94.

35. Yang $\mathrm{W}, \mathrm{Xu} \mathrm{X}$, Liu X, et al. Treat-to-target comparison between once daily biphasic insulin aspart 30 and insulin glargine in Chinese and Japanese insulin-naive subjects with type 2 diabetes. Curr. Med. Res. Opin. 2013;29(12):1599-608.

36. Flint A, Raben A, Astrup A, Holst JJ. Glucagon-like peptide 1 promotes satiety and suppresses energy intake in humans. J Clin Invest. 1998;101(3): 515-20.

37. Men P, Qu S, Luo W, Li C, Zhai S. Comparison of lixisenatide in combination with basal insulin vs other insulin regimens for the treatment of patients with type 2 diabetes inadequately controlled by basal insulin: Ssstematic review, network metaanalysis and cost-effectiveness analysis. Diabetes Obes Metab. 2020;22(1):107-15.

38. Park H-Y, An S-N, Park S-S, et al. Cost effectiveness of insulin glargine/lixisenatide for patients with type 2 diabetes inadequately controlled on basal insulin in South Korea. Yakhak Hoeji. 2019;63(1): $1-14$. 